\title{
Associations between red blood cell variants and malaria among children and adults from three areas of Uganda: a prospective cohort study
}

\author{
Elijah Kakande ${ }^{1 *} \mathbb{D}$, Bryan Greenhouse ${ }^{2}$, Francis Bajunirwe ${ }^{3}$, Chris Drakeley ${ }^{4}$, Joaniter I. Nankabirwa', \\ Andrew Walakira', Samuel L. Nsobya' ${ }^{1}$, Agaba Katureebe1, John Rek', Emmanuel Arinaitwe' , Philip J. Rosenthal², \\ Moses R. Kamya', Grant Dorsey² and Isabel Rodriguez-Barraquer²
}

\begin{abstract}
Background: Multiple red blood cell (RBC) variants appear to offer protection against the most severe forms of Plasmodium falciparum malaria. Associations between these variants and uncomplicated malaria are less clear.

Methods: Data from a longitudinal cohort study conducted in 3 sub-counties in Uganda was used to quantify associations between three red blood cell variants $\mathrm{Hb}$ [AA, AS, S (rs334)], alpha thalassaemia $3.7 \mathrm{~kb}$ deletion, and glucose6-phosphate dehydrogenase deficiency A-(G6PD 202A genotype) and malaria incidence, parasite prevalence, parasite density (a measure of anti-parasite immunity) and body temperature adjusted for parasite density (a measure of anti-disease immunity). All analyses were adjusted for age, average household entomological inoculation rate, and study site. Results for all variants were compared to those for wild type genotypes.

Results: In children, HbAS was associated, compared to wild type, with a lower incidence of malaria (IRR $=0.78$, $95 \% \mathrm{Cl} 0.66-0.92, p=0.003)$, lower parasite density upon infection ( $P R=0.66,95 \% \mathrm{Cl} 0.51-0.85, p=0.001)$, and lower body temperature for any given parasite density $\left(-0.13{ }^{\circ} \mathrm{C}, 95 \% \mathrm{Cl}-0.21,-0.05, \mathrm{p}=0.002\right)$. In children, HbSS was associated with a lower incidence of malaria (IRR $=0.17,95 \% \mathrm{Cl} 0.04-0.71, \mathrm{p}=0.02$ ) and lower parasite density upon infection ( $\mathrm{PR}=0.31,95 \% \mathrm{Cl} 0.18-0.54, \mathrm{p}<0.001)$. $\mathrm{a}-$ - /aa thalassaemia, was associated with higher parasite prevalence in both children and adults $(R R=1.23,95 \% \mathrm{Cl} 1.06-1.43, p=0.008$ and $R R=1.52,95 \% \mathrm{Cl} 1.04-2.23, p=0.03$, respectively). G6PD deficiency was associated with lower body temperature for any given parasite density only among male hemizygote children $\left(-0.19^{\circ} \mathrm{C}, 95 \% \mathrm{Cl}-0.31,-0.06, \mathrm{p}=0.003\right)$.
\end{abstract}

Conclusion: RBC variants were associated with non-severe malaria outcomes. Elucidation of the mechanisms by which they confer protection will improve understanding of genetic protection against malaria.

Keywords: Red blood cell variants, Erythrocyte, Malaria, Plasmodium, Sickle hemoglobin, Thalassemia

*Correspondence: rkakande@idrc-uganda.org

${ }^{1}$ Infectious Diseases Research Collaboration, 2C Nakasero Hill Road, Kampala, Uganda

Full list of author information is available at the end of the article

\section{Background}

Multiple red blood cell (RBC) variants are associated with protection against severe Plasmodium falciparum malaria. Studies conducted in numerous populations have consistently shown that people with HbAS have a $70-90 \%$ reduced risk of severe malaria [1-4]. Similarly,

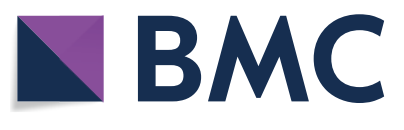

(c) The Author(s) 2020. This article is licensed under a Creative Commons Attribution 4.0 International License, which permits use, sharing, adaptation, distribution and reproduction in any medium or format, as long as you give appropriate credit to the original author(s) and the source, provide a link to the Creative Commons licence, and indicate if changes were made. The images or other third party material in this article are included in the article's Creative Commons licence, unless indicated otherwise in a credit line to the material. If material is not included in the article's Creative Commons licence and your intended use is not permitted by statutory regulation or exceeds the permitted use, you will need to obtain permission directly from the copyright holder. To view a copy of this licence, visit http://creativeco mmons.org/licenses/by/4.0/. The Creative Commons Public Domain Dedication waiver (http://creativecommons.org/publicdomain/ zero/1.0/) applies to the data made available in this article, unless otherwise stated in a credit line to the data. 
both $\alpha-/ \alpha \alpha$ and $\alpha-/ \alpha-$ thalassaemia reduce the risk of severe malaria by $20-40 \%$ [5-7]. The association between glucose-6-phosphate dehydrogenase [G6PD] deficiency and severe malaria is less clear $[4,8]$. Some studies reported that G6PD protects both heterozygous females and hemizygous males from severe malaria [9], others reported protection for only hemizygous males [10], and others reported no protection [8]. Mechanisms through which these variants confer protection appear to be complex and may include restriction of red blood cell invasion and intracellular growth, increased destruction of parasitized red cells, and improved cell mediated and humoral immune responses [11-17].

While protective associations between certain RBC variants and severe malaria have been shown consistently [7, 18], associations with uncomplicated malaria have been less straightforward. Multiple studies showed reduced risk of malaria [19-24] and lower parasite densities $[4,25,26]$ with HbAS compared to wild-type. For alpha thalassaemia, studies suggested both protection against and enhancement of malaria [5, 6, 27, 28]. For G6PD deficiency, studies in Africa [29-32], but not Asia [8, 33-35] suggested protection against uncomplicated malaria. Some discrepancies in findings might be attributed to differences between studies in human populations, transmission settings, and study designs.

Data from three cohorts conducted in areas of low, moderate, and high malaria transmission intensity in Uganda was used to quantify associations between three red blood cell variants and uncomplicated malaria outcomes. Notably, the cohort studies included passive surveillance for symptomatic malaria, active surveillance for $P$. falciparum infection, and regular entomological surveys to quantify transmission risk.

\section{Methods}

\section{Study design, sites, and population}

Prospective cohort studies were conducted at three sites. Study sites were Walukuba, Jinja District, a peri urban area in South Central Uganda with a low malaria transmission intensity (annual entomological inoculation rate (aEIR) or number of infective mosquito bites per person per year $=2.8$ ); Kihihi, Kanungu District, a predominantly rural area in south western Uganda with moderate malaria transmission $(\mathrm{aEIR}=32)$; and Nagongera, Tororo District, a predominantly rural area in south eastern Uganda with a very high transmission intensity $(\mathrm{aEIR}=310)$ [36] until initiation of indoor residual spraying of insecticide in late 2014 [37]. Details on how the study households and participants were selected has been described elsewhere [36]. Briefly, in each of the 3 sub-counties 100 households were randomly enrolled. Households were included if they had at least one child between 6 months and 10 years of age and at least one adult resident providing informed consent. All children and one adult primary care giver from each household meeting the eligibility criteria were invited to participate. Participants were followed-up until they reached 11 years of age or until they were withdrawn from the study either voluntarily or because they failed to comply with study visits.

\section{Study procedures and follow-up}

Study procedures and follow up have been described in detail [36-38]. Briefly, all participants were given an insecticide treated bed net at enrollment and were followed for all their healthcare needs at dedicated study clinics open 7 days each week. Participants were provided free health care and clinic travel expenses, but received no other incentives to participate. Episodes of malaria were diagnosed by passive case detection and defined as a history of fever within the past $24 \mathrm{~h}$ or an elevated temperature $\left(\geq 38.0{ }^{\circ} \mathrm{C}\right.$ tympanic) with a positive malaria thick blood smear. Episodes of malaria were treated with artemether-lumefantrine (uncomplicated malaria) or intravenous quinine or artesunate (complicated malaria), following national guidelines at the time of the studies. In addition, participants were asked to make a routine visit to the study clinic every 3 months. At each of these visits, a thick blood smear was evaluated to assess for parasitaemia. The cohorts were dynamic, such that all newly eligible children were enrolled, and participants were withdrawn when they reached 11 years of age.

Household level EIR was estimated using data from entomologic surveys carried out concurrently with the cohort studies, as previously described [39]. Briefly, one CDC light trap collection was carried out monthly in the main sleeping room of each house. The average household EIR was calculated as the average number of female Anopheles mosquitoes collected per night multiplied by the proportion of mosquitoes containing sporozoites at each site.

\section{Laboratory methods}

Presence of three RBC variants, the sickle locus (rs334), $-3.7 \alpha$ - thalassemia and G6PD-G202A (rs1050828), was tested as previously described [40]. Briefly, genes of interest were amplified, amplicons subjected to mutationspecific restriction endonuclease digestion (for sickle haemoglobin and G6PD deficiency), reaction products resolved by electrophoresis, and genotypes determined based on the sizes of reaction products. For assessment of parasitaemia, thick blood smears were stained with $2 \%$ Giemsa, allowed to dry for $30 \mathrm{~min}$, and read by experienced laboratory technologists. Parasite densities were calculated by counting the number of asexual parasites 


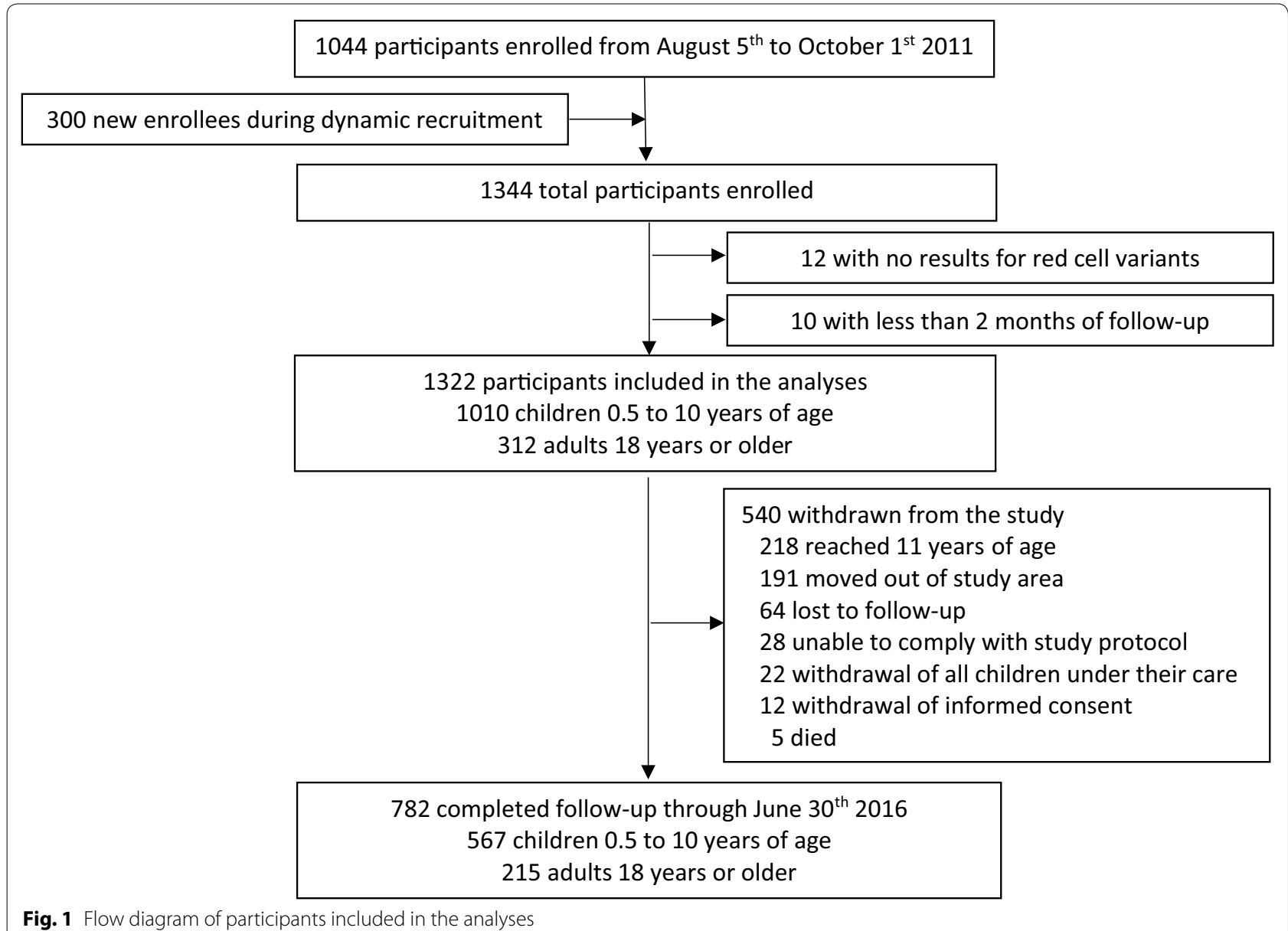

per 200 leukocytes or per 500 leukocytes if the count was less than 10 asexual parasites per 200 leukocytes, assuming a leukocyte count of 8000 per microlitre [41]. A blood smear was considered negative if the examination of 100 high power fields did not reveal any asexual parasites. For quality control, blood smears were read by a second microscopist, and discrepancies resolved by a third microscopist.

\section{Statistical methods}

All data were collected using standardized forms and subsequently entered into Microsoft access before transfer to STATA (Version 14; STATA Corp., College Station, TX, USA) and R for analyses [42]. The data analysed were for participants enrolled from August 2011 through December 2014 and followed through June 2016. Study participants were included in the analyses if they had results for at least one $\mathrm{RBC}$ variant tested and at least 2 months of follow-up. Associations between RBC variants and malaria incidence were quantified using negative binomial regression models with measures of association expressed as the incidence rate ratio (IRR). Associations between $\mathrm{RBC}$ variants and parasite prevalence at the time of each routine visit were quantified using log-binomial generalized estimating equations with robust standard errors to generate prevalence ratios (PR). Effects of RBC variants on two components of anti-malarial immunity, anti-parasite immunity (ability to control parasite densities upon infection) and anti-disease immunity (ability to tolerate higher parasite density without developing fever) were also investigated. To model these outcomes, generalized additive models (GAMS) were used as previously described [38]. The outcome of interest in the antiparasite immunity model was the $\log 10$ parasite density in parasite positive visits, and the outcome of interest in the anti-disease model was the measured temperature, adjusted for parasite density. All analyses were adjusted for age, average household level EIR, and study site, and included random effects at the individual and household level to account for clustering. For each RBC variant, the group with wild type genotype was chosen as the reference. 
Table 1 Baseline characteristics of participants included in the analyses

\begin{tabular}{|c|c|c|}
\hline Characteristic & Children, $\mathrm{n}(\%)^{\mathrm{a}}$ & Adults, $\mathrm{n}(\%)^{\mathrm{a}}$ \\
\hline \multicolumn{3}{|l|}{ Study site } \\
\hline Walukuba & $318(31.5 \%)$ & $113(36.2 \%)$ \\
\hline Kihihi & $357(35.4 \%)$ & $95(30.5 \%)$ \\
\hline Nagongera & $335(33.2 \%)$ & $104(33.3 \%)$ \\
\hline \multicolumn{3}{|l|}{ Gender } \\
\hline Male & $516(51.1 \%)$ & $19(6.1 \%)$ \\
\hline Female & $494(48.9 \%)$ & $293(93.9 \%)$ \\
\hline \multicolumn{3}{|c|}{ Haemoglobin variant } \\
\hline AA & $808(80.7 \%)$ & $242(78.3 \%)$ \\
\hline AS & $188(18.8 \%)$ & $67(21.7 \%)$ \\
\hline SS & $5(0.5 \%)$ & $0(0 \%)$ \\
\hline No result & 9 & 3 \\
\hline \multicolumn{3}{|c|}{ Alpha thalassaemia variant } \\
\hline Normal & $585(60.3 \%)$ & $200(66.0 \%)$ \\
\hline$a-/ a a$ & $335(34.5 \%)$ & $84(27.7 \%)$ \\
\hline$a-/-a$ & $50(5.2 \%)$ & $19(6.3 \%)$ \\
\hline No result & 40 & 9 \\
\hline \multicolumn{3}{|c|}{ G6PD genotype (male) } \\
\hline Normal & 455 (89.4\%) & $15(79.0)$ \\
\hline Hemizygotes & $54(10.6 \%)$ & $4(21.1 \%)$ \\
\hline No result & 7 & 0 \\
\hline \multicolumn{3}{|c|}{ G6PD genotype (female) } \\
\hline Normal & $370(75.5 \%)$ & $232(79.5 \%)$ \\
\hline Heterozygotes & $108(22.0 \%)$ & $55(18.8 \%)$ \\
\hline Homozygotes & $12(2.4 \%)$ & $5(1.7 \%)$ \\
\hline No result & 4 & 1 \\
\hline
\end{tabular}

a Proportion among those with results available

\section{Results}

\section{Characteristics of participants in the study}

Of 1344 participants enrolled in the cohort studies, 1322 (98.4\%) were included in the analyses and 782 of these (59.2\%) were followed through the end of June 2016 (Fig. 1). A total of 1010 (76.4\%) participants were children 0.5-10 years of age and $312(23.6 \%)$ were adult primary care givers. Approximately half the children and $94 \%$ of adults were female (Table 1). Overall, the prevalence of all 3 red blood cell variants, Hb variant, alpha thalassaemia, and G6PD deficiency were highly variable across the three sites with Nagongera having the highest prevalence and Kihihi the lowest (Additional file 1: Table S1).

\section{Associations between RBC variants and malaria incidence}

The overall incidence of malaria across the 3 sites was 1.60 episodes per person year (PPY) among children and 0.31 episodes PPY among adults. Among children, HbAS was associated with a $22 \%$ lower incidence of malaria $(\mathrm{IRR}=0.78,95 \%$ CI $0.66-0.92, \mathrm{p}=0.003)$ and HbSS with an $83 \%$ lower incidence of malaria (IRR $=0.17,95 \% \mathrm{CI}$ $0.04-0.71, \mathrm{p}=0.02$ ), compared to children with wild type genotypes (Table 2). In contrast, among adults there was no association between $\mathrm{HbAS}$ and malaria incidence $(\mathrm{IRR}=0.99,95 \%$ CI $0.66-1.49, \mathrm{p}=0.98)$. For both children and adults there were no significant associations between alpha thalassaemia or G6PD deficiency and malaria incidence (Table 2).

\section{Associations between RBC variants and prevalence of microscopic parasitaemia}

The prevalence of microscopic parasitaemia at the time of routine visits across the 3 sites was $15.8 \%$ among children and $4.5 \%$ among adults. There were no significant associations between HbAS and parasite prevalence among children or adults. Children with HbSS had a $69 \%$ lower prevalence of parasitaemia compared to those with wild type genotype $(\mathrm{PR}=0.31,95 \% \mathrm{CI} 0.18-0.54, \mathrm{p}<0.001)$ (Table 3$)$. For both children and adults, $\alpha-/ \alpha \alpha$ thalassaemia, but not $\alpha-/ \alpha-$ thalassaemia, was associated with a higher parasite prevalence compared to that in wild type individuals $(\mathrm{RR}=1.2395 \% \mathrm{CI} 1.06-1.43, \mathrm{p}=0.008$ and $\mathrm{RR}=1.52$, 95\% CI 1.04-2.23, $\mathrm{p}=0.03$, respectively). For children and adults there were no significant associations between G6PD deficiency and microscopic parasitaemia (Table 3).

\section{Associations between RBC variants and parasite densities upon infection (anti-parasite immunity) in children} Among children who were parasitaemic, the overall geometric mean parasite density was 11,400 parasites per $\mu \mathrm{L}$ (95\% CI 10,800-12,100). On average, children with HbAS had lower parasite densities by a factor of 0.66 (95\% CI $0.51-0.85, \mathrm{p}=0.001)$ compared to children with wild type genotype. There were no significant associations between alpha thalassaemia or G6PD deficiency and parasite densities (Table 4).

Associations between RBC variants and body temperature upon infection (anti-disease immunity) in children

Among children who were parasitaemic, the mean tympanic temperature was $37.6{ }^{\circ} \mathrm{C}$ (IQR 37.6-37.7). In models adjusted for parasite density, parasitaemic children with $\mathrm{HbAS}$ had body temperatures that were on average $0.13{ }^{\circ} \mathrm{C}$ lower (95\% CI, 0.05-0.21, $\left.\mathrm{p}=0.002\right)$ at the time of the visit, compared to children with wild type genotype. There were no significant associations between alpha thalassaemia and body temperature among parasitaemic children. Upon stratification, parasitaemic male children that were G6PD hemizygotes had temperatures that were $0.19{ }^{\circ} \mathrm{C}$ lower (95\% CI 0.06-0.31, $\mathrm{p}=0.003$ ) compared those with the wild type G6PD genotype. There were no significant associations between G6PD deficiency 
Table 2 Associations between RBC variants and malaria incidence

\begin{tabular}{|c|c|c|c|c|c|c|c|c|c|}
\hline \multirow[t]{2}{*}{ Age group } & \multirow[t]{2}{*}{ Red cell variants } & \multirow[t]{2}{*}{ Variant } & \multirow{2}{*}{$\begin{array}{l}\text { Malaria } \\
\text { episodes }\end{array}$} & \multirow{2}{*}{$\begin{array}{l}\text { Person years } \\
\text { of follow-up }\end{array}$} & \multirow{2}{*}{$\begin{array}{l}\text { Incidence } \\
\text { of malaria } \\
\text { PPY }\end{array}$} & \multicolumn{2}{|l|}{ Unadjusted } & \multicolumn{2}{|l|}{ Adjusted* } \\
\hline & & & & & & IRR (95\% Cl) & $p$-value & IRR $(95 \% \mathrm{Cl})$ & $p$-value \\
\hline \multirow[t]{11}{*}{ Children } & \multirow[t]{3}{*}{ Haemoglobin variant } & $\mathrm{AA}$ & 4612 & 2762 & 1.67 & Reference & & Reference & \\
\hline & & AS & 818 & 620 & 1.32 & $0.77(0.64-0.94)$ & 0.009 & $0.78(0.66-0.92)$ & 0.003 \\
\hline & & SS & 3 & 13.4 & 0.22 & $0.16(0.03-0.78)$ & 0.02 & $0.17(0.04-0.71)$ & 0.02 \\
\hline & \multirow{3}{*}{$\begin{array}{l}\text { Alpha thalassaemia } \\
\text { variant }\end{array}$} & Normal & 3233 & 2061 & 1.57 & Reference & & Reference & \\
\hline & & $a-/ a a$ & 1769 & 1106 & 1.60 & $1.00(0.85-1.18)$ & 0.98 & $1.04(0.91-1.20)$ & 0.56 \\
\hline & & $a-/-a$ & 251 & 150 & 1.67 & $0.97(0.68-1.38)$ & 0.88 & $1.19(0.87-1.62)$ & 0.27 \\
\hline & \multirow[t]{5}{*}{ G6PD genotype } & Normal (male) & 2680 & 1597 & 1.68 & Reference & & Reference & \\
\hline & & Hemizygotes & 374 & 170 & 2.20 & $1.18(0.85-1.63)$ & 0.33 & $0.93(0.71-1.22)$ & 0.61 \\
\hline & & Normal (female) & 1768 & 1224 & 1.44 & Reference & & Reference & \\
\hline & & Heterozygotes & 484 & 355 & 1.36 & $0.91(0.70-1.18)$ & 0.46 & $0.80(0.63-1.01)$ & 0.06 \\
\hline & & Homozygotes & 72 & 40.5 & 1.78 & $1.21(0.60-2.44)$ & 0.59 & $0.89(0.51-1.57)$ & 0.70 \\
\hline \multirow[t]{10}{*}{ Adults } & \multirow[t]{2}{*}{ Haemoglobin variant } & $\mathrm{AA}$ & 300 & 936 & 0.32 & Reference & & Reference & \\
\hline & & AS & 69 & 252 & 0.27 & $0.85(0.56-1.30)$ & 0.46 & $0.99(0.66-1.49)$ & 0.98 \\
\hline & \multirow{3}{*}{$\begin{array}{l}\text { Alpha thalassaemia } \\
\text { variant }\end{array}$} & Normal & 252 & 783 & 0.32 & Reference & & Reference & \\
\hline & & $a-/ a a$ & 102 & 318 & 0.32 & $1.01(0.68-1.48)$ & 0.98 & $1.10(0.76-1.59)$ & 0.63 \\
\hline & & $a-/-a$ & 11 & 70.0 & 0.16 & $0.50(0.22-1.15)$ & 0.10 & $0.58(0.25-1.33)$ & 0.20 \\
\hline & \multirow[t]{5}{*}{ G6PD genotype } & Normal (male) & 13 & 55.1 & 0.23 & Reference & & Reference & \\
\hline & & Hemizygotes & 3 & 19.4 & 0.16 & $0.66(0.15-2.90)$ & 0.58 & $0.98(0.16-5.85)$ & 0.98 \\
\hline & & Normal (female) & 294 & 995 & 0.30 & Reference & & Reference & \\
\hline & & Heterozygotes & 73 & 191 & 0.38 & $1.26(0.81-1.97)$ & 0.31 & $1.13(0.74-1.72)$ & 0.58 \\
\hline & & Homozygotes & 1 & 11.2 & 0.09 & $0.39(0.03-4.41)$ & 0.45 & $0.40(0.04-3.92)$ & 0.43 \\
\hline
\end{tabular}

* Adjusted for age, average household EIR, and study site

and temperature among female parasitaemic children (Table 5).

\section{Discussion}

This study used data from 1322 participants enrolled in three longitudinal cohorts in Uganda to investigate associations between RBC variants and several outcomes of uncomplicated P. falciparum infection. Compared to children with wild type haemoglobin, children with HbAS had a reduced risk of incident malaria, developed lower parasite densities upon infection, and tolerated higher parasite densities without developing fever. Associations with other $\mathrm{RBC}$ variants were less straightforward: $\alpha-/ \alpha \alpha$ thalassaemia was associated with higher parasite prevalence in both children and adults; G6PD deficient male hemizygote children, but not females, tolerated higher parasite densities without developing fever. These findings are consistent with recent findings from Uganda and elsewhere showing that HbAS is associated with protection in children, but not adults, from symptomatic malaria $[2,7,19]$ and is also associated with low parasite densities during symptomatic disease [4, 19, 43]. Children with HbSS were also strongly protected against incident malaria. Furthermore, HbSS children were also less likely to develop high temperatures for any given parasite density, as compared to children with wild type haemoglobin (i.e.; they had higher anti-disease immunity). The mechanisms by which HbAS protects the host against symptomatic and severe disease have been extensively explored and appear to be complex. Some of the proposed mechanisms include increased sickling of parasitized RBCs, enhanced phagocytosis of parasitized RBCs, reduced intraerythrocytic parasite growth, and decreased cytoadherence via reduced expression of $P$. falciparum Erythrocyte Membrane Protein 1 (PfEMP1) $[11,44]$. The lack of protection associated with HbAS in adults is likely due to the predominant role played by acquired immunity among older age groups in highly endemic regions.

In contrast to results for $\mathrm{HbS}$, there were no protective associations between alpha thalassaemia and any of the outcomes measured. In fact, although $\alpha-/ \alpha \alpha$ thalassaemia has been associated with protection against both severe $[5,6,18,22]$ and uncomplicated forms of malaria $[27,28]$ in this study of uncomplicated malaria it was associated with a higher parasite prevalence in both children and adults as compared to the wild type. Similar associations have been previously suggested [45]. 
Table 3 Associations between RBC variants and prevalence of microscopic parasitaemia at the time of each routine visit

\begin{tabular}{|c|c|c|c|c|c|c|c|}
\hline \multirow[t]{2}{*}{ Age group } & \multirow[t]{2}{*}{ Red cell variants } & \multirow[t]{2}{*}{ Variant } & \multirow[t]{2}{*}{ Parasite prevalence } & \multicolumn{2}{|l|}{ Unadjusted } & \multicolumn{2}{|l|}{ Adjusted* } \\
\hline & & & & PR $(95 \% \mathrm{Cl})$ & p-value & PR $(95 \%$ Cl) & p-value \\
\hline \multirow[t]{11}{*}{ Children } & Haemoglobin variant & AA & 2488/15,830 (15.7\%) & Reference & & Reference & \\
\hline & & AS & $597 / 3636(16.4 \%)$ & $1.07(0.89-1.30)$ & 0.46 & $0.95(0.80-1.13)$ & 0.57 \\
\hline & & SS & $3 / 66(4.6 \%)$ & $0.31(0.14-0.68)$ & 0.004 & $0.31(0.18-0.54)$ & $<0.001$ \\
\hline & Alpha thalassaemia variant & Normal & 1621/11,664 (13.9\%) & Reference & & Reference & \\
\hline & & $\mathrm{alpha}^{+}(\mathrm{a}-/ \mathrm{aa})$ & 1272/6397 (19.9\%) & $1.45(1.24-1.70)$ & $<0.001$ & $1.23(1.06-1.43)$ & 0.008 \\
\hline & & $\operatorname{alpha}^{0}(a-/-a)$ & $127 / 937(13.6 \%)$ & $0.96(0.66-1.40)$ & 0.83 & $0.98(0.66-1.44)$ & 0.91 \\
\hline & G6PD genotype & Normal (male) & 1593/9147 (17.4\%) & Reference & & Reference & \\
\hline & & Hemizygotes & 194/1030 (18.8\%) & $1.09(0.81-1.48)$ & 0.57 & $0.86(0.65-1.14)$ & 0.30 \\
\hline & & Normal (female) & $887 / 7039(12.6 \%)$ & Reference & & Reference & \\
\hline & & Heterozygotes & $372 / 2062(18.0 \%)$ & $1.35(1.04-1.75)$ & 0.02 & $1.13(0.87-1.45)$ & 0.36 \\
\hline & & Homozygotes & 46/243 (18.9\%) & $1.38(0.75-2.54)$ & 0.30 & $0.92(0.53-1.59)$ & 0.76 \\
\hline \multirow[t]{10}{*}{ Adults } & Haemoglobin variant & AA & 187/3952 (4.7\%) & Reference & & Reference & \\
\hline & & AS & $37 / 1050$ (3.5\%) & $0.72(0.45-1.15)$ & 0.17 & $0.74(0.45-1.22)$ & 0.24 \\
\hline & Alpha thalassaemia variant & Normal & 128/3307 (3.9\%) & Reference & & Reference & \\
\hline & & $\mathrm{alpha}^{+}(\mathrm{a}-/ \mathrm{aa})$ & $81 / 1332(6.1 \%)$ & $1.59(1.08-2.34)$ & 0.02 & $1.52(1.04-2.23)$ & 0.03 \\
\hline & & $a-/-a$ & $15 / 290(5.2 \%)$ & $1.35(0.76-2.42)$ & 0.30 & $1.16(0.63-2.14)$ & 0.64 \\
\hline & G6PD genotype & Normal (male) & $8 / 229(3.5 \%)$ & reference & & reference & \\
\hline & & Hemizygotes & 7/79 (8.9\%) & $2.48(0.72-8.52)$ & 0.15 & $5.10(0.58-44.9)$ & 0.14 \\
\hline & & Normal (female) & $173 / 3792(4.6 \%)$ & Reference & & Reference & \\
\hline & & Heterozygotes & $37 / 880(4.2 \%)$ & $0.87(0.58-1.31)$ & 0.51 & $0.77(0.52-1.15)$ & 0.20 \\
\hline & & Homozygotes & $3 / 50(6.0 \%)$ & $1.38(0.42-4.50)$ & 0.59 & $1.34(0.44-4.05)$ & 0.61 \\
\hline
\end{tabular}

* Adjusted for age, average household EIR, and study site

Table 4 Associations between red cell variants and parasite densities (anti-parasite immunity) in parasitaemic children

\begin{tabular}{|c|c|c|c|c|c|}
\hline \multirow[t]{2}{*}{ Red cell variants } & \multirow[t]{2}{*}{ Variant } & \multicolumn{2}{|l|}{ Unadjusted } & \multicolumn{2}{|l|}{ Adjusted* } \\
\hline & & $\begin{array}{l}\text { Change in } \log ^{10} \text { parasite } \\
\text { density }(95 \% \mathrm{Cl})\end{array}$ & $p$-value & $\begin{array}{l}\text { Change in } \log ^{10} \text { parasite } \\
\text { density }(95 \% \mathrm{Cl})\end{array}$ & $p$-value \\
\hline \multirow[t]{3}{*}{ Haemoglobin variant } & AA & Reference & & Reference & \\
\hline & AS & $-0.25(-0.37,-0.12)$ & $<0.001$ & $-0.18(-0.29,-0.07)$ & 0.001 \\
\hline & SS & $-0.4(-1.33,0.53)$ & 0.40 & $-0.11(-0.95,0.73)$ & 0.80 \\
\hline \multirow[t]{3}{*}{ Alpha thalassaemia variant } & Normal & Reference & & Reference & \\
\hline & $a-/ a a$ & $-0.20(-0.30,-0.10)$ & $<0.001$ & $-0.06(-0.14,0.03)$ & 0.19 \\
\hline & $a-/-a$ & $0.09(-0.14,0.31)$ & 0.45 & $0.04(-0.15,0.22)$ & 0.71 \\
\hline \multirow[t]{5}{*}{ G6PD genotype } & Normal (male) & Reference & & Reference & \\
\hline & Hemizygotes & $-0.01(-0.22,0.20)$ & 0.92 & $-0.01(-0.18,0.17)$ & 0.94 \\
\hline & Normal (female) & Reference & & Reference & \\
\hline & Heterozygotes & $-0.18(-0.34,-0.01)$ & 0.04 & $-0.05(-0.19,0.09)$ & 0.51 \\
\hline & Homozygotes & $0.05(-0.34,0.44)$ & 0.80 & $0.12(-0.21,0.45)$ & 0.46 \\
\hline
\end{tabular}

* Adjusted for age, average household EIR, and study site

However, $\alpha-/ \alpha \alpha$ thalassaemia did not have any association with incidence of symptomatic disease, parasite densities or anti-disease immunity.

Interestingly, the results from this study suggest that G6PD deficiency may play a role in anti-disease immunity. For any given parasite density, G6PD hemizygous parasitaemic male children had lower temperatures than wild type parasitaemic male children upon P. falciparum infection. Thus, G6PD deficiency may be associated with increased ability to tolerate high parasite 
Table 5 Associations between RBC variants and temperature adjusted for parasite density (anti-disease immunity) in parasitaemic children

\begin{tabular}{|c|c|c|c|c|c|}
\hline \multirow[t]{2}{*}{ Red cell variants } & \multirow[t]{2}{*}{ Variant } & \multicolumn{2}{|l|}{ Unadjusted } & \multicolumn{2}{|l|}{ Adjusted* } \\
\hline & & $\begin{array}{l}\text { Change in temperature } \\
\text { in }{ }^{\circ} \mathrm{C}(95 \% \mathrm{Cl})\end{array}$ & p-value & $\begin{array}{l}\text { Change in temperature } \\
\text { in }{ }^{\circ} \mathrm{C}(95 \% \mathrm{Cl})\end{array}$ & p-value \\
\hline \multirow[t]{3}{*}{ Haemoglobin variant } & $\mathrm{AA}$ & Reference & & Reference & \\
\hline & AS & $-0.13(-0.22,-0.04)$ & 0.003 & $-0.13(-0.21,-0.05)$ & 0.002 \\
\hline & SS & $0.09(-0.68,0.86)$ & 0.82 & $0.22(-0.52,0.96)$ & 0.56 \\
\hline \multirow[t]{3}{*}{ Alpha thalassaemia variant } & Normal & Reference & & Reference & \\
\hline & $a-/ a a$ & $-0.10(-0.17,-0.03)$ & 0.003 & $-0.09(-0.21,0.02)$ & 0.11 \\
\hline & $a-/-a$ & $-0.08(-0.24,0.08)$ & 0.31 & $-0.16(-0.41,0.08)$ & 0.20 \\
\hline \multirow[t]{5}{*}{ G6PD genotype } & Normal (male) & Reference & & Reference & \\
\hline & Hemizygotes & $-0.12(-0.25,0.01)$ & 0.07 & $-0.19(-0.31,-0.06)$ & 0.003 \\
\hline & Normal (female) & Reference & & Reference & \\
\hline & Heterozygotes & $-0.12(-0.24,0.01)$ & 0.07 & $-0.09(-0.21,0.02)$ & 0.11 \\
\hline & Homozygotes & $-0.08(-0.37,0.20)$ & 0.57 & $-0.16(-0.41,0.08)$ & 0.20 \\
\hline
\end{tabular}

* Adjusted for parasite density, age, average household EIR, and study site

densities without developing fever. However, the protective effect against symptomatic malaria was seen only in males, and not in heterozygous or homozygous females. There is considerable evidence to suggest that G6PD protects both male [10] and female [30, 46, 47] African children against severe malaria. However, information regarding G6PD protection from uncomplicated malaria is less clear albeit with a leaning towards protection for female children $[4,8,24]$.

Results for associations between G6PD deficiency and uncomplicated malaria remain inconclusive.

This study had several limitations. First, sample sizes were small for certain groups, notably the SS and G6PD homozygous genotypes, which limited the ability to evaluate their associations with malaria outcomes. However, these genotypes occurred at expected frequencies in these populations and sample sizes would be prohibitively large to study them in a cohort. Second, parasitaemia was measured using microscopy, which is much less sensitive than molecular techniques for identifying parasites [48-50]. Impacts of RBC variants on sub-microscopic parasitaemia were not studied. Third, the degree of fever measured during symptomatic malaria may have been influenced by children receiving antipyretics prior to evaluation in the clinic. However, the majority of the patients presented to the study clinics within 24-48 $\mathrm{h}$ of symptom onset. Moreover, participants were encouraged to present to the clinic for all their health care needs as soon as they were unwell. Fourth, the study did not explore associations between red blood cell variants and other measures of protective immunity such as $P$. falciparum antibodies. Finally, there were very few cases of severe malaria, precluding exploration of associations between host polymorphisms and severe malaria.

\section{Conclusion}

In areas endemic for falciparum malaria, RBC variants may play an important role in protecting children against malaria. First, both HbAS and alpha thalassaemia are associated with decreased incidence of severe malaria. These strong associations probably explain the persistence of these balanced polymorphisms in human populations at risk of falciparum malaria. Second, some polymorphisms also appear to protect against uncomplicated malaria. Identified associations with HbAS provide the strongest evidence of protection, with evidence for lower risks of malarial incidence and enhancement of both anti-parasite and anti-disease immunity. G6PD deficiency may provide additional protection against progression to symptomatic disease, with evidence for enhanced anti-disease immunity. While the mechanisms by which common RBC variants protect against malaria remain incompletely understood, their associations with protection against malaria underline the exceptional selective pressure of malaria on the human genome.

\section{Supplementary information}

Supplementary information accompanies this paper at https://doi. org/10.1186/s12936-020-3105-3.

Additional file 1: Table S1. Prevalence of red blood cell variants stratified by study site and age group. 


\section{Abbreviations}

G6PD: glucose-6-phosphate dehydrogenase; HbAS: haemoglobin AS genotype; HbSS: haemoglobin SS genotype; HbS: haemoglobin S genotype; PCR: polymerase chain reaction; LAMP: loop mediated isothermal amplification; GAMS: generalized additive models; aEIR: annual entomological inoculation rate

\section{Acknowledgements}

We are grateful to the study team and the Infectious Diseases Research Collaboration for the administrative and technical support. We thank the study participants and their families for participating in the study.

\section{Authors' contributions}

GD, MK, PJR, EA and EK conceived and designed the study. JR, AK, EK, EA, SN and AW Performed recruitment of study participants and coordinated laboratory experiments. GD, BF, JN, BG, IRB and EK performed statistical analyses and wrote the manuscript. All authors read and approved the final manuscript.

\section{Funding}

This work was funded by the National Institute of Allergy and Infectious Diseases of the National Institute of Health as part of the International Centers of Excellence in Malaria Research (ICEMR) program (Grant Number: U19AI089674). EK was funded by NIH Fogarty International Center, Training in Malaria Research in Uganda program (TW007375).

JIN is supported by the Fogarty International Center (Emerging Global Leader Award Grant Number K43TW010365. The content of the manuscript is solely the responsibility of the authors.

\section{Availability of data and materials}

All data has been made publicly available at https:/clinepidb.org/ce/app.

\section{Ethical approval and consent to participate}

The study was approved by the IRBs of all the participating institutions which included the Uganda National Council of Science and Technology (UNCST), Makerere University School of Medicine - Research and Ethical Committee (SOMREC), University of California, San Francisco Committee for Human Research (UCSF-CHR) and London School of Hygiene and Tropical Medicine Ethics Committee. Written informed consent to participate in the study was obtained from all study participants (or their designate).

\section{Consent for publication}

Not applicable.

\section{Competing interests}

The authors declare that they have no competing interests.

\begin{abstract}
Author details
${ }^{1}$ Infectious Diseases Research Collaboration, 2C Nakasero Hill Road, Kampala, Uganda. ${ }^{2}$ Department of Medicine, University of California, San Francisco, CA 94110, USA. ${ }^{3}$ Department of Community Health, Mbarara University of Science and Technology, Mbarara, Uganda. ${ }^{4}$ Immunity and Infection, London School of Hygiene \& Tropical Medicine, Keppel Street, London WC1E 7HT, UK.
\end{abstract}

Received: 14 October 2019 Accepted: 7 January 2020

Published online: 15 January 2020

\section{References}

1. Taylor SM, Cerami C, Fairhurst RM. Hemoglobinopathies: slicing the Gordian knot of Plasmodium falciparum malaria pathogenesis. PLoS Pathog. 2013:9:e1003327.

2. Kwiatkowski DP. How malaria has affected the human genome and what human genetics can teach us about malaria. Am J Human Genet. 2005;77:171-92.

3. Williams TN. Human red blood cell polymorphisms and malaria. Curr Opin Microbiol. 2006;9:388-94.

4. Lopera-Mesa TM, Doumbia S, Konaté D, Anderson JM, Doumbouya M, Keita AS, et al. Effect of red blood cell variants on childhood malaria in Mali: a prospective cohort study. Lancet Haematol. 2015;2:e140-9.
5. Wambua S, Mwangi TW, Kortok M, Uyoga SM, Macharia AW, Mwacharo $J K$, et al. The effect of a+-thalassaemia on the incidence of malaria and other diseases in children living on the coast of Kenya. PLoS Med. 2006;3:e158.

6. Williams T, Wambua S, Uyoga S. Both heterozygous and homozygous thalassemia protect against severe and fatal Plasmodium falciparum malaria on the coast of Kenya. Blood. 2005;106:368-71.

7. Taylor SM, Parobek CM, Fairhurst RM. Haemoglobinopathies and the clinical epidemiology of malaria: a systematic review and meta-analysis. Lancet Infect Dis. 2012;12:457-68.

8. Mbanefo EC, Ahmed AM, Titouna A, Elmaraezy A, Trang NTH, Long NP, et al. Association of glucose-6-phosphate dehydrogenase deficiency and malaria: a systematic review and meta-analysis. Sci Rep. 2017;7:45963.

9. Clark TG, Fry AE, Auburn S, Campino S, Diakite M, Green A, et al. Allelic heterogeneity of G6PD deficiency in West Africa and severe malaria susceptibility. Eur J Human Genet. 2009:17:1080-5.

10. Guindo A, Fairhurst RM, Doumbo OK, Wellems TE, Diallo DA. X-linked G6PD deficiency protects hemizygous males but not heterozygous females against severe malaria. PLoS Med. 2007;4:e66.

11. Gong L, Parikh S, Rosenthal PJ, Greenhouse B. Biochemical and immunological mechanisms by which sickle cell trait protects against malaria. Malar J. 2013:12:317.

12. Friedman MJ, Roth EF, Nagel RL, Trager W. The role of hemoglobins C, S, and $\mathrm{Nbalt}$ in the inhibition of malaria parasite development in vitro. Am Trop Med Hyg. 1979;28:777-80

13. Luzzatto L, Nwachuku-Jarrett E, Reddy S. Increased sickling of parasitised erythrocytes as mechanism of resistance against malaria in the sickle-cell trait. Lancet. 1970;295:319-22.

14. Wajcman H, Galacteros F. [Glucose 6-phosphate dehydrogenase deficiency: a protection against malaria and a risk for hemolytic accidents] (in French). C R Biol. 2004:327:711-20.

15. Cappadoro M, Giribaldi G, O'Brien E, Turrini F, Mannu F, Ulliers D, et al. Early phagocytosis of glucose-6-phosphate dehydrogenase (G6PD)deficient erythrocytes parasitized by Plasmodium falciparum may explain malaria protection in G6PD deficiency. Blood. 1998:92:2527-34

16. Le Hesran JY, Personne I, Personne P, Fievet N, Dubois B, Beyemé M, et al. Longitudinal study of Plasmodium falciparum infection and immune responses in infants with or without the sickle cell trait. Int Epidemiol. 1999;28:793-8.

17. Verra F, Simpore J, Warimwe GM, Tetteh KK, Howard T, Osier FH, et al. Haemoglobin $C$ and $S$ role in acquired immunity against Plasmodium falciparum malaria. PLOS ONE. 2007:2:e978.

18. Mockenhaupt FP, Ehrhardt S, Gellert S, Otchwemah RN, Dietz E, Anemana SD, et al. a+-thalassemia protects African children from severe malaria. Blood. 2004;104:2003-6.

19. Williams TN, Mwangi TW, Wambua S, Alexander ND, Kortok M, Snow RW, et al. Sickle cell trait and the risk of Plasmodium falciparum malaria and other childhood diseases. J Infect Dis. 2005;192:178-86.

20. Gong L, Maiteki-Sebuguzi C, Rosenthal PJ, Hubbard AE, Drakeley CJ, Dorsey $\mathrm{G}$, et al. Evidence for both innate and acquired mechanisms of protection from Plasmodium falciparum in children with sickle cell trait. Blood. 2012;119:3808-14.

21. Elguero E, Délicat-Loembet LM, Rougeron V, Arnathau C, Roche B, Becquart $P$, et al. Malaria continues to select for sickle cell trait in Central Africa. Proc Natl Acad Sci USA. 2015;112:7051-4.

22. Mpimbaza A, Walakira A, Ndeezi G, Katahoire A, Karamagi C, Nsobya $\mathrm{SL}$, et al. Associations between erythrocyte polymorphisms and risks of uncomplicated and severe malaria in Ugandan children: a case control study. PLOS ONE. 2018;13:e0203229.

23. Modiano D, Luoni G, Sirima BS, Simporé J, Verra F, Konaté A, et al. Haemoglobin $C$ protects against clinical Plasmodium falciparum malaria. Nature. 2001:414:305-8.

24. Clark TD, Greenhouse B, Njama-Meya D, Nzarubara B, MaitekiSebuguzi C, Staedke SG, et al. Factors determining the heterogeneity of malaria incidence in children in Kampala, Uganda. J Infect Dis. 2008;198:393-400.

25. Awotua-Efebo O, Alikor E, Nkanginieme K. Malaria parasite density and splenic status by ultrasonography in stable sickle-cell anaemia (HbSS) children. Niger J Med. 2004;13:40-3. 
26. Mangano VD, Kabore Y, Bougouma EC, Verra F, Sepulveda N, Bisseye $C$, et al. Novel insights into the protective role of hemoglobin S and C against Plasmodium falciparum parasitemia. J Infect Dis. 2015;212:626-34.

27. Maitland K, Williams T, Bennett S, Newbold C, Peto T, Viji J, et al. The interaction between Plasmodium falciparum and P. vivax in children on Espiritu Santo island, Vanuatu. Trans R Soc Trop Med Hyg. 1996;90:614-20.

28. Enevold A, Lusingu JP, Mmbando B, Alifrangis M, Lemnge MM, Bygbjerg $I C$, et al. Reduced risk of uncomplicated malaria episodes in children with alpha+-thalassemia in northeastern Tanzania. Am J Trop Med Hyg. 2008;78:714-20.

29. Luzzatto L, Usanga EA, Reddy S. Glucose-6-phosphate dehydrogenase deficient red cells: resistance to infection by malarial parasites. Science. 1969;164:839-42.

30. Ruwende C, Khoo S, Snow R, Yates S, Kwiatkowski D, Gupta S, et al. Natural selection of hemi-and heterozygotes for G6PD deficiency in Africa by resistance to severe malaria. Nature. 1995;376:246-9.

31. Allison A. Malaria and glucose-6-phosphate dehydrogenase deficiency. Nature. 1963;197:609.

32. Segeja M, Mmbando BP, Kamugisha M, Akida J, Savaeli Z, Minja D, et al. Prevalence of glucose-6-phosphate dehydrogenase deficiency and haemoglobin S in high and moderate malaria transmission areas of Muheza, north-eastern Tanzania. Tanzania J Health Res. 2008;10:9-13.

33. Kruatrachue M, Charoenlarp P, Chongsuphajaisiddhi T, Harinasuta C. Erythrocyte glucose-6-phosphate dehydrogenase and malaria in Thailand. Lancet. 1962;2:1183-6.

34. Jalloh A, Tantular I, Pusarawati S, Kawilarang A, Kerong H, Lin K, et al. Rapid epidemiologic assessment of glucose-6-phosphate dehydrogenase deficiency in malaria-endemic areas in Southeast Asia using a novel diagnostic kit. Trop Med Int Health. 2004;9:615-23.

35. Tantular I, Iwai K, Lin K, Basuki S, Horie T, Htay H, et al. Field trials of a rapid test for G6PD deficiency in combination with a rapid diagnosis of malaria. Trop Med Int Health. 1999;4:245-50.

36. Kamya MR, Arinaitwe E, Wanzira H, Katureebe A, Barusya C, Kigozi SP, et al. Malaria transmission, infection, and disease at three sites with varied transmission intensity in Uganda: implications for malaria control. Am J Trop Med Hyg. 2015;92:903-12.

37. Katureebe A, Zinszer K, Arinaitwe E, Rek J, Kakande E, Charland K, et al. Measures of malaria burden after long-lasting insecticidal net distribution and indoor residual spraying at three sites in Uganda: a prospective observational study. PLoS Med. 2016;13:e1002167.

38. Rodriguez-Barraquer I, Arinaitwe E, Jagannathan P, Kamya MR, Rosentha PJ, Rek J, et al. Quantification of anti-parasite and anti-disease immunity to malaria as a function of age and exposure. Elife. 2018;7:e35832.
39. Kilama M, Smith DL, Hutchinson R, Kigozi R, Yeka A, Lavoy G, et al. Estimating the annual entomological inoculation rate for Plasmodium falciparum transmitted by Anopheles gambiae s.l. using three sampling methods in three sites in Uganda. Malar J. 2014;13:111.

40. Walakira A, Tukwasibwe S, Kiggundu M, Verra F, Kakeeto P, Ruhamyankaka E, et al. Marked variation in prevalence of malaria-protective human genetic polymorphisms across Uganda. Infection, genetics and evolution. 2017;55:281-7

41. WHO. Basic malaria microscopy_part I: learner's guide. Geneva: World Health Organization; 2010.

42. Team RC. R: a language and environment for statistical computing. 2013.

43. Migot-Nabias F, Mombo L, Luty A, Dubois B, Nabias R, Bisseye C, et al. Human genetic factors related to susceptibility to mild malaria in Gabon. Genes Immun. 2000;1:435-41.

44. Fairhurst RM, Bess CD, Krause MA. Abnormal PfEMP1/knob display on Plasmodium falciparum-infected erythrocytes containing hemoglobin variants: fresh insights into malaria pathogenesis and protection. Microbes Infect. 2012;14:851-62.

45. Kuesap J, Chaijaroenkul W, Rungsihirunrat K, Pongjantharasatien K, NaBangchang K. Coexistence of malaria and thalassemia in malaria endemic areas of Thailand. Korean J Parasitol. 2015;53:265-70.

46. Uyoga S, Ndila CM, Macharia AW, Nyutu G, Shah S, Peshu N, et al. Glucose-6-phosphate dehydrogenase deficiency and the risk of malaria and other diseases in children in Kenya: a case-control and a cohort study. Lancet Haematol. 2015;2:e437-44.

47. Orimadegun AE, Sodeinde O. Features and outcomes of malaria infection in glucose-6-phosphate-dehydrogenase normal and deficient Nigerian children. J Vector Borne Dis. 2014;51:33-9.

48. Rek J, Katrak S, Obasi H, Nayebare P, Katureebe A, Kakande E, et al. Characterizing microscopic and submicroscopic malaria parasitaemia at three sites with varied transmission intensity in Uganda. Malar J. 2016;15:470.

49. Lucchi NW, Gaye M, Diallo MA, Goldman IF, Ljolje D, Deme AB, et al. Evaluation of the illumigene malaria LAMP: a robust molecular diagnostic tool for malaria parasites. Sci Rep. 2016;6:36808

50. Mens P, Spieker N, Omar S, Heijnen M, Schallig H, Kager P. Is molecular biology the best alternative for diagnosis of malaria to microscopy? A comparison between microscopy, antigen detection and molecular tests in rural Kenya and urban Tanzania. Trop Med Int Health. 2007:12:238-44.

\section{Publisher's Note}

Springer Nature remains neutral with regard to jurisdictional claims in published maps and institutional affiliations.
Ready to submit your research? Choose BMC and benefit from:

- fast, convenient online submission

- thorough peer review by experienced researchers in your field

- rapid publication on acceptance

- support for research data, including large and complex data types

- gold Open Access which fosters wider collaboration and increased citations

- maximum visibility for your research: over 100M website views per year

At BMC, research is always in progress.

Learn more biomedcentral.com/submissions 